\title{
Transoral Laser Microsurgery
}

National Cancer Institute

\section{Source}

National Cancer Institute. Transoral Laser Microsurgery. NCI Thesaurus. Code C91840.

A minimally invasive procedure in which a surgeon performs tumor resection through the mouth using a microscope for visualization and a CO2 laser for incisions. 